\title{
What is a shock wave to an explosive molecule?
}

\author{
C. M. Tarver
}

This article was submitted to

$12^{\text {th }}$ American Physical Society Topical Conference, Atlanta, GA., June 24-29, 2001

\section{June 12, 2001}

U.S. Department of Energy

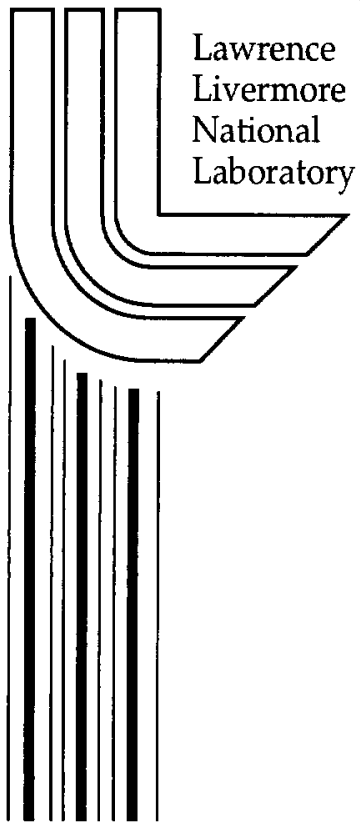




\section{DISCLAIMER}

This document was prepared as an account of work sponsored by an agency of the United States Government. Neither the United States Government nor the University of California nor any of their employees, makes any warranty, express or implied, or assumes any legal liability or responsibility for the accuracy, completeness, or usefulness of any information, apparatus, product, or process disclosed, or represents that its use would not infringe privately owned rights. Reference herein to any specific commercial product, process, or service by trade name, trademark, manufacturer, or otherwise, does not necessarily constitute or imply its endorsement, recommendation, or favoring by the United States Government or the University of California. The views and opinions of authors expressed herein do not necessarily state or reflect those of the United States Government or the University of California, and shall not be used for advertising or product endorsement purposes.

This is a preprint of a paper intended for publication in a journal or proceedings. Since changes may be made before publication, this preprint is made available with the understanding that it will not be cited or reproduced without the permission of the author.

This work was performed under the auspices of the United States Department of Energy by the University of California, Lawrence Livermore National Laboratory under contract No. W-7405-Eng-48.

This report has been reproduced directly from the best available copy.

Available electronically at http://www.doc.gov/bridge

Available for a processing fee to U.S. Department of Energy

And its contractors in paper from

U.S. Department of Energy

Office of Scientific and Technical Information

P.O. Box 62

Oak Ridge, TN 37831-0062

Telephone: (865) 576-8401

Facsimile: (865) 576-5728

E-mail: reports@adonis.osti.gov

Available for the sale to the public from

U.S. Department of Commerce

National Technical Information Service

5285 Port Royal Road

Springfield, VA 22161

Telephone: (800) 553-6847

Facsimile: (703) 605-6900

E-mail: orders@ntis.fedworld.gov

Online ordering: http://www.ntis.gov/ordering.htm

OR

Lawrence Livermore National Laboratory

Technical Information Department's Digital Library

http://www.llnl.gov/tid/Library.html 


\title{
WHAT IS A SHOCK WAVE TO AN EXPLOSIVE MOLECULE?
}

\author{
Craig M. Tarver \\ Lawrence Livermore National Laboratory \\ P.O. Box 808, L-282, Livermore, CA 94551
}

\begin{abstract}
An explosive molecule is a metastable chemical species that reacts exothermically given the correct stimulus. Impacting an explosive with a shock wave is a "wake-up call" or "trigger" which compresses and heats the molecule. The energy deposited by the shock wave must be distributed to the vibrational modes of the explosive molecule before chemical reaction can occur. If the shock pressure and temperature are high enough and last long enough, exothermic chemical decomposition can lead to the formation of a detonation wave For gaseous, liquid, and perfect single crystal solid explosives, after an induction time, chemical reaction begins at or near the rear boundary of the charge. This induction time can be calculated by high pressure, high temperature transition state theory. A "superdetonation" wave travels through the preshocked explosive until it overtakes the initial shock wave and then slows to the steady state Chapman-Jouguet (C-J) velocity. In heterogeneous solid explosives, initiation of reaction occurs at "hot spots" created by shock compression. If there is a sufficient number of large and hot enough "hot spots," these ignition sites grow creating a pressure pulse that overtakes the leading shock front causing detonation. Since the chemical energy is released well behind the leading shock front of a detonation wave, a mechanism is required for this energy to reinforce the leading shock front and maintain its overall constant velocity. This mechanism is the amplification of pressure wavelets in the reaction zone by the process of de-excitation of the initially highly vibrationally excited reaction product molecules. This process leads to the development of the threedimensional structure of detonation waves observed for all explosives. In a detonation wave, the leading shock wave front becomes a "burden" for the explosive molecule to sustain by its chemical energy release.
\end{abstract}

\section{INTRODUCTION}

What is a shock wave to an explosive molecule? There are several answers to this question depending upon the strength and time duration of the shock pulse. Since an explosive molecule (or a mixture of fuel and oxidizer molecules) is inherently metastable, it requires only an increase in its internal energy to overcome its activation energy barrier to reaction. This decomposition process may eventually become highly exothermic and cause deflagration (subsonic reaction) or detonation (supersonic reaction). So a shock wave is the "wake-up call" or the "trigger" that causes the molecule to release its chemical energy. The shock pulse must be of sufficient strength and time duration or self-sustaining exothermic chemical reaction does not occur. In a heterogeneous solid explosive, a weak shock wave can create a compressed material that does not react when subjected to subsequent shock waves. Strong shock waves create reactive flows in their wake. These reactive flows can couple to, reinforce and strengthen the shock front. The result is a detonation wave, in which the leading shock wave front is sustained by the chemical energy released behind it. Then the shock front is not only a "trigger" but also a "burden" to the explosive molecule since it must be sustained by its exothermic chemical reaction.

Therefore a shock wave can he mạny different things to an explosive molecule. In this paper the current state of knowledge anil future restarch directions for each of these regimes are briefly discussed in order of increasing pressure.

\section{NON-SHOCK IMPACT IGNITION}

When a heterogeneous solid explosive charge is subjected to a low velocity impact that produces a 
few kilobars of pressure, a Iwo-stage compression wave is formed. This wave consists of an elastic wave that propagates through the explosive at longitudinal sound velocity followed by a plastic wave traveling at lower velocity $(1,2)$. Within the flow field produced by the plastic wave, regions of the explosive can be heated by void collapse, friction, shear, and other possible mechanisms (3). "Hot spots" are formed and can ignite and grow into an explosive energy release. Most of these ignitions result in subsonic deflagration waves driven by heat transfer from the hot reaction products into the surrounding explosive molecules. Impact ignition is one of the most important explosive safety concems, because it is caused by the smallest amount of energy delivered to the explosive molecules. Several tests have been developed to study impact: drop hammers; drop weight impact machines; Skid tests; the Susan test; etc. In recent years, the Steven Test at LLNL (4) and its modified version at LANL (5) have been used to yield quantitative experimental data that can be simulated with reactive flow computer models. The Steven Test and other impact studies have resulted in an improved understanding of impact ignition.

\section{WEAK SHOCK COMPRESSION}

At slightly higher pressures, the elastic and plastic waves merge into a relatively weak shock wave $(1,2)$. For homogeneous explosives, these shocks compress and heat the explosive molecules slightly, but little or no chemical decomposition occurs. For some heterogeneous solid explosives, there exists a narrow range of shock pressures in which all of the voids and other inhomogeneities can be compressed without creating growing hot spot reactions. The resulting fully dense explosive material can not be shock initiated by subsequent strong shock waves or even detonation waves. This phenomenon is called "dead pressing" or "shock desensitization"(6). Depending on the application, this can be a useful or a frustrating property of explosive molecules.

\section{HOMOGENEOUS EXPLOSIVES}

Homogeneous explosives include gases, liquids without bubbles or suspended solids, and perfect crystals of solid explosives. In these materials, planar shock waves uniformly compress and heat the explosive molecules. There has long been some debate about the definition of the thickness of a shock wave. Zeldovich and Raizer (7) define the width of a shock wave as the distance at which the viscosity and heat conduction become negligible. This occurs within a few molecular collisions in a gas. The internal modes of gaseous explosive molecules are also becoming excited: translational modes (a few collisions); rotational modes (tens of collisions); and vibrational modes (hundreds of collisions). These equilibration processes have long been studied in shock tubes (8). Internal energy equilibration is now being studied in shocked liquid and solid explosives by Dlotl et al. (9) and Fayer et al(10). In condensed phases, the phonon modes are excited followed by multi-phonon excitation of the lowest frequency vibrational modes and then the higher frequency modes by multi-phonon uppumping and internal vibrational energy redistribution (IVR)(11). Once the explosive molecules have attained vibrational equilibrium, chemical decomposition can begin.

For gaseous explosives, these equilibration processes which precede chemical reaction are easily measured since they can be lengthened to nanosecond or even microsecond time frames by dilution with iner1 gases or by the use of low initial pressures. The calculation of these states is also straight forward, because the perfect gas law applies. The initial reaction rates for the dissociation of the weakest chemical bond present in the explosive molecule/mixture are also easily measured in shock tube experiments and calculated using unimolecular Arrhenius chemical kinetics. If the shock wave heats the explosive molecules to temperatures at which sufficient dissociation occurs before the shock compression ends and rarefaction cooling begins, the newly formed atoms react with surrounding molecules. An exothermic chain reaction process follows in which reaction product gases are formed in highly vibrationally excited states (12). These excited products either undergo reactive collisions with the surrounding explosive molecules or nonreactive collisions with their neighbors in which one or more quanta of vibrational energy is transferred. Some collisions are "super-collisions"(13) in which several quanta of vibrational energy are transferred. Since reaction rates increase rapidly with each quanta of vibrational energy available, reactive collisions dominate and the main chemical reactions are extremely fast. Once the chain reaction process is completed, the remainder of the reaction zone is dominated by the de-excitation of highly vibrationally excited product molecules as chemical 
equilibrium is approached. This de-excitation process controls the length of the reaction wone and provides the chemical energy necessary for shock wave amplification during shock-to-detonation transition (SDT) and self-sustaining detonation.

The Non-Equilibrium Zeldovich - von NeumannDoring (NEZND) theory of detonation (12,14-17) was developed to explain the various non-equilibrium processes that precede and follow chemical energy relcase in self-sustaining detonation waves. As pressure wavelets pass through the subsonic reaction zone, they are amplified by vibrational de-excitation processes. The opposite effect - shock wave damping by a non-equilibrium gas that lacks vibrational energy after expansion through a nozzle - is a wellknown phenomenon (7). The pressure wavelets then interact with the main shock front and replace the energy lost during compression, acceleration and heating of the explosive molecules. During shock initiation, this interaction process increases the shock front pressure and velocity. If the initial shock wave is accelerated to a velocity at which chemical reaction occurs close to the front, then selfsustaining detonation occurs. The pressure wavelet amplification process then provides the required chemical energy by developing a three-dimensional Mach stem shock front structure. This leading shock wave front is still a "wake-up call" or "trigger" for explosive reaction, but it is also a "burden" for the explosive molecules to sustain at a constant supersonic velocity with their energy .

The three-dimensional structures of detonation waves have been observed for gaseous, liquid and solid explosives (18). In gaseous detonations, the details are very well known and several excellent reviews of the subject are available (19). For liquid and perfect single crystal solid explosives, the situation is much more complex and thus more difficult to observe and calculate than in gases. The high initial densities of the condensed phases make the measurement and calculation of the states attained behind a shock wave more difficult, because the processes now take tens and hundreds of picoseconds and the perfect gas law does not apply. The distribution of the shock compression energy between the potential (cold compression) energy of the unreacted liquid or solid and its thermal energy is a complex function of shock strength. The lack of voids, cracks, particle boundaries, etc. eliminates "hot spot" formation as an initiation mechanism. If the shock compressed state lasts long enough for exothermic reaction to begin at this shock temperature, initiation of occurs at or near the boundary of the explosive charge in the molecules first impacted by the shock. This "thermal explosion" creates a "superdetonation" wave that propagates through the precompressed explosive at a velocity in excess of its equilibrium ChapmanJouguet $(\mathrm{C}-\mathrm{J})$ velocity. When this wave overtakes the leading shock wave, its velocity decreases rapidly until steady state velocity is attained. This phenomenon has been measured and calculated for several detonating liquids (20) and solid perfect crystals (21). Liquid explosives exhibit a wide range of shock sensitivity (22). Perfect single crystals of relatively sensitive solid explosives like PETN can be shock initiatiated (21), but single crystals of HMX can not be initiated by a detonation wave from an HMX-based plastic bonded explosive (6).

The "induction" time for the initial "thermal explosion" can be calculated using the high pressure, high temperature transition state theory. Experimental data for unimolecular gas phase reaction rates under low temperature shock conditions obeys the usual Arrhenius law:

$$
K=A e^{-E / R T}
$$

where $\mathrm{K}$ is the reaction rate constant, $\mathrm{A}$ is a frequency factor, $E$ is the activation energy, and $T$ is temperature, at low temperatures, but "fall-off" to less rapid rates of increase at high temperatures (23). Nanosecond reaction zone measurements for solid explosives overdriven to pressures and temperatures exceeding those attained in self-sustaining detonation waves have shown that the reaction rates increase very slowly with shock temperature (24). Eyring (25) attributed this "falloff" in unimolecular rates at the extreme temperature and density states attained in shock and detonation waves to the close proximity of vibrational states, which causes the high frequency mode that becomes the transition state to rapidly equilibrate with the surrounding modes by IVR. These modes form a "pool" of vibrational energy in which the energy required for decomposition is shared. Any large quantity of vibrational energy that a specific mode receives from an excitation process is shared among the modes before reaction occurs. Conversely, sufficient vibrational energy from the entire pool of oscillators is statistically present in the Iransition state long enough to cause reaction. When the total energy in the vibrational modes equals the activation energy, the reaction ratc constant $\mathrm{K}$ is: 


$$
\mathrm{K}=(\mathbf{k T / h}) \mathrm{e}^{-\mathrm{s}} \sum_{\mathrm{i}=0}^{\mathrm{s}-1}(\mathrm{E} / \mathrm{RT})^{\mathrm{i}} \mathrm{e}^{-E / R T} / \mathrm{i} \text { ! }
$$

where $k, h$, and $R$ are Boltzmann's, Planck's, and the gas constant, respectively, and $s$ is the number of neighboring vibrational modes interacting with the transition state. The main effect of this rapid IVR among $s+1$ modes at high densities and temperatures is to decrease the rate constant dependence on temperature. Reasonable reaction rate constants were calculated for detonating solids and liquids using Eq. (2) with realistic equations of state and values of $s(15)$. For the lower temperatures attained in shock initiation of homogeneous liquid and solid explosives, the reaction rate constants calculated using Eq. (2) are larger than those predicted by Eq. (1). Reaction rate constants from Eqs. (1) and (2) are compared to induction time results for gaseous norbornene, liquid nitromethane, and single crystal PETN in Figs. $1-3$, respectively (16). Despite uncertainties in the calculated shock temperatures for various equations of state, it is clear that $\mathrm{Eq}$. (2) agrees quite well with all three sets of data using reasonable values of $s$. Thus high pressure, high temperature transition state theory accurately calculates induction times for shock induced reactions during shock initiation and detonation of homogeneous gaseous, liquid, and solid explosives.

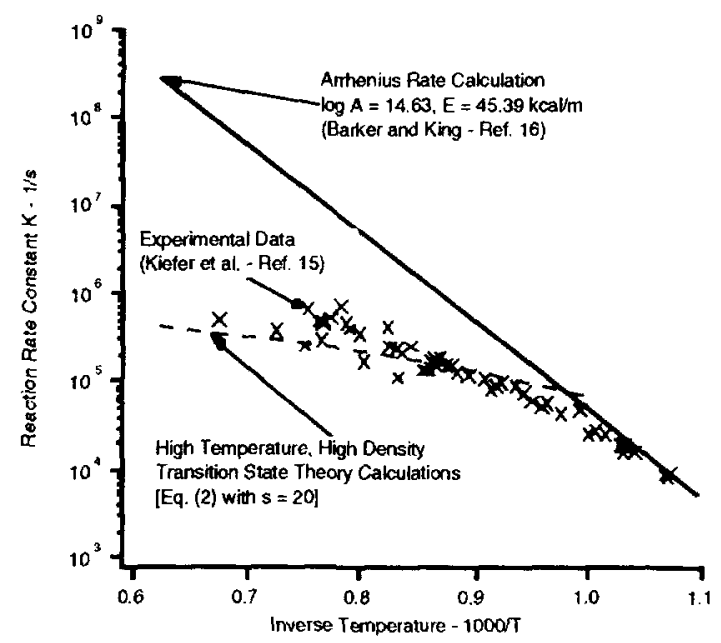

FIGURE 1. Reaction rate constant versus inverse temperature for the unimolecular decomposition of norbornene

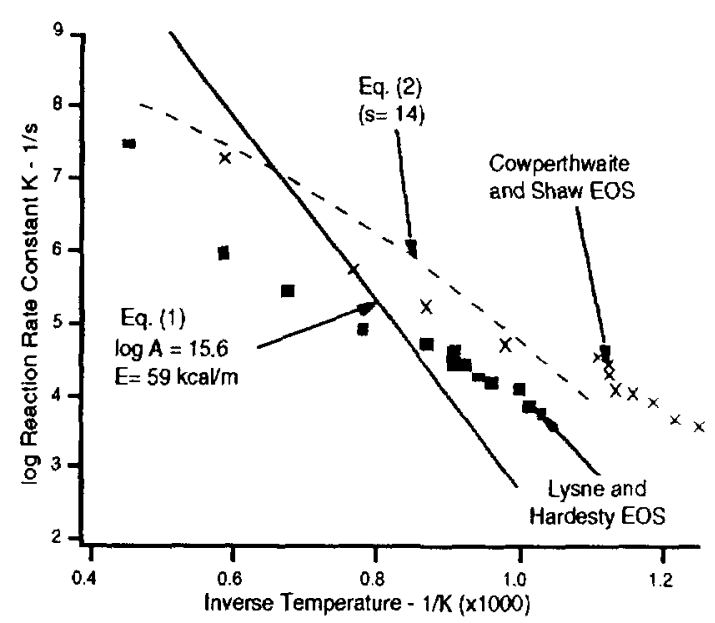

FIGURE 2. Reaction rate constants for nitromethane as functions of shock temperature

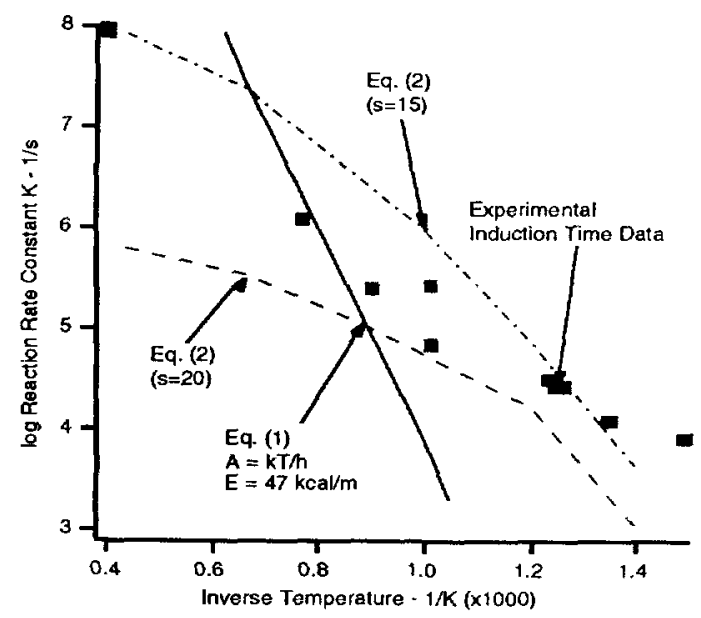

FIGURE 3. Reaction rate constants for single crystal PETN as functions of shock temperature

\section{HETEROGENEOUS EXPLOSIVES}

For heterogeneous explosives (liquids with bubbles or suspended solid particles and pressed or cast solids with voids, binders, metal particles, etc.), an initiating shock wave does not have to heat the entire material to the point of thermal explosion. Thermal energy is concentrated in local sites by the physical processes of void collapse, friction, shear, dislocation pile-up, etc. Liquid explosives which contain bubbles can undergo partial reactions known 
as low velocity detonation (LVD) at heated sites created by collapsing voids. LVD can propagate long distances in pipes and is a major safety concern. LVD can cease to propagate or transition to full detonation in various scenarios (26).

It has long been known that shock initiation of solid explosives is controlled by ignition of hot spots (3). How large and how hot does a hot spot have to be to react and begin to grow? Critical conditions for the growth or failure of hot spots in HMX- and TATB-based explosives have been calculated using multistep Arrhenius kinetic chemical decomposition models derived from thermal explosion experiments (27). Figure 4 shows the calculated critical spherical hot spot temperatures in HMX and TATB. Once ignited, the growth rates of reacting hot spots into neighboring solid explosive particles and the interactions of several growing hot spots have been calculated for various geometries (28). Figure 5 shows the times required for spherical HMX particles of various radii to complete deflagrate inwardly under various boundary temperature conditions. These relatively long times show that large explosive particles must fragment, producing smaller particles with more reactive surface area for hot gaseous reaction products to ignite. As growing hot spots coalesce at high pressures and temperatures, the transition from shock induced reaction to detonation occurs very rapidly. The buildup of pressure and particle velocity behind the shock wave front during shock initiation has been thoroughly studied using embedded gauge $(29,30)$ and

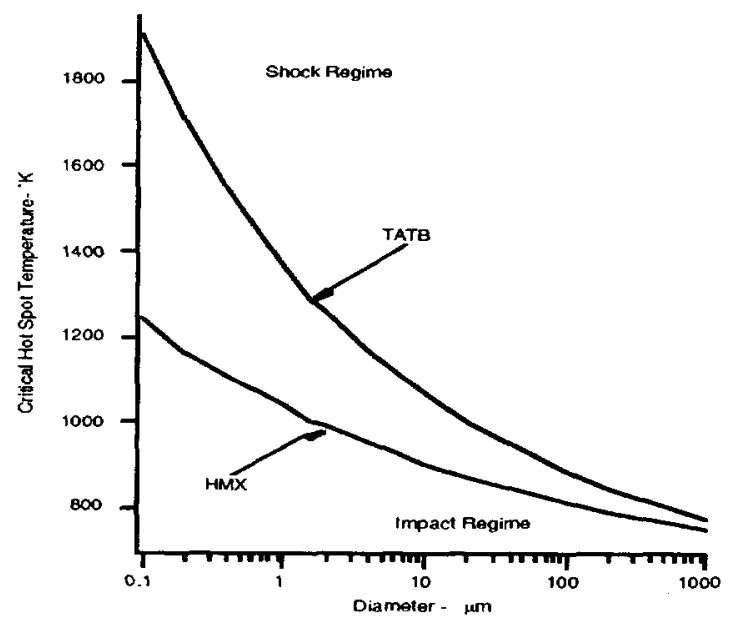

Figure 4. Critical spherical hot spot temperatures in HMX and TATB at various diameters laser interferometric (31) techniques. These reactive flows have been modeled in multidimensional codes by the Ignition and Growth model of shock initiation and detonation (32). Figure 6 shows measured and calculated pressure histories obtained for a shock initiation experiment on HMX-based LX-04 (29).

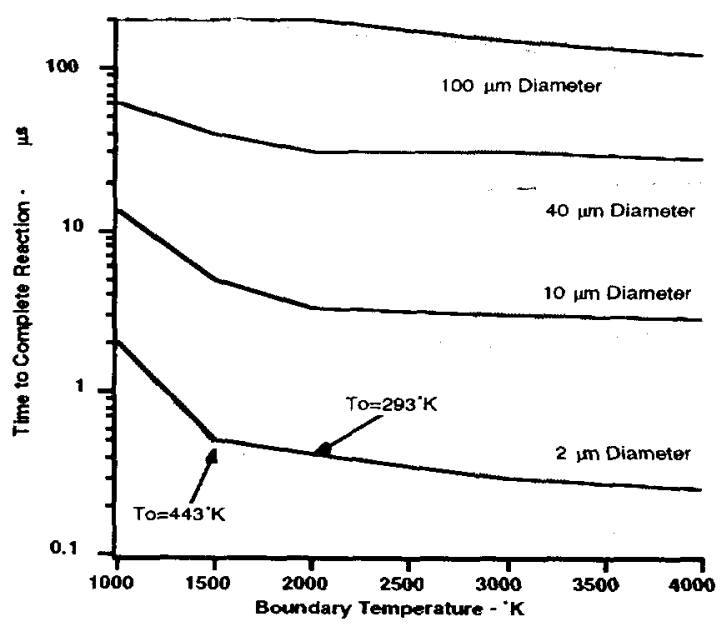

FIGURE 5. Reaction times for HMX particles

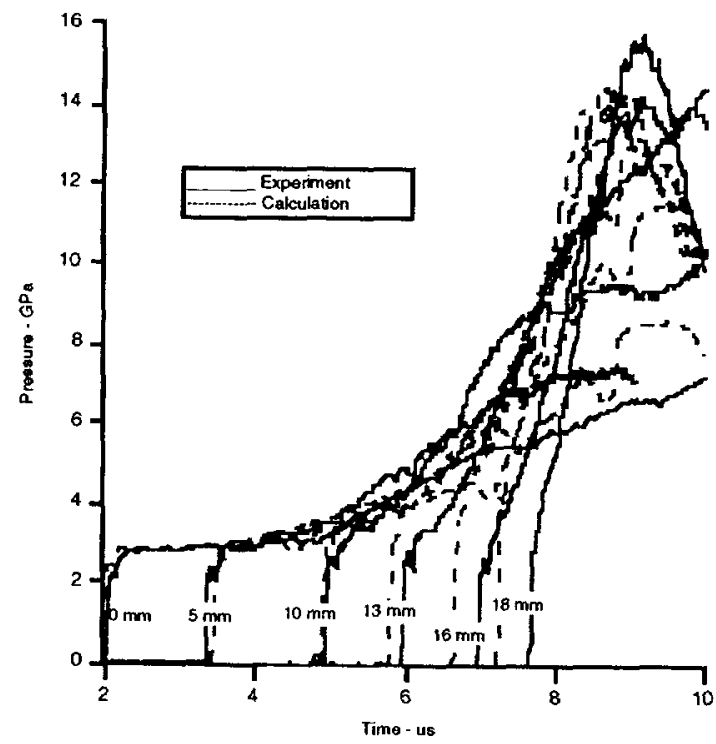

FIGURE 6. Pressure histories for ambient temperature $\mathrm{LX}-04$ shock initiated by a Teflon flyer plate at $0.956 \mathrm{~mm} / \mu \mathrm{s}$

Detonation wave reaction zone structures in solid explosives and their metal acceleration properties have also been measured by embedded gauges and 
laser interferometry and calculated by the Ignition and Growth model (33). Figure 7 shows the measured and calculated interface velocity histories for detonating LX-17, a TATB-based explosive, impacting various salt crystals (33). Figure 8 illustrates the measured and calculated free surface velocities of $0.267 \mathrm{~mm}$ thick tantalum discs driven by $19.871 \mathrm{~mm}$ of detonating LX-17

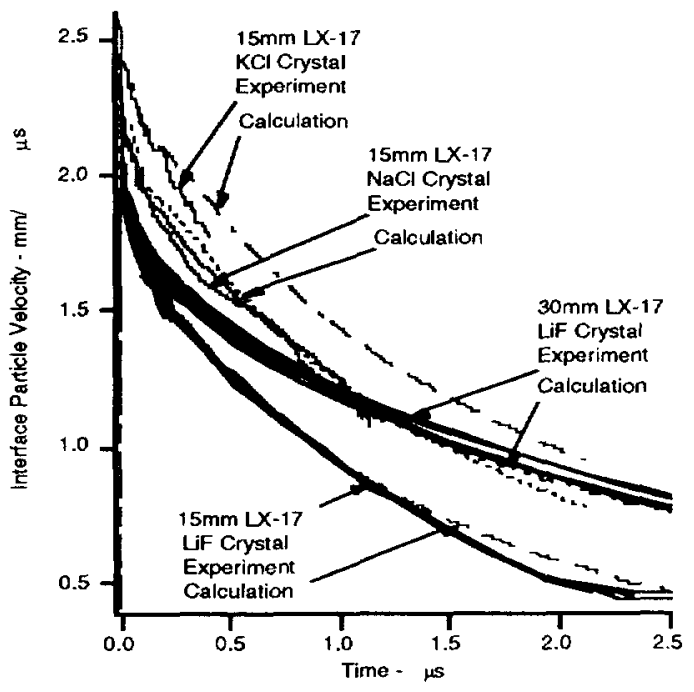

FIGURE 7. Interface particle velocity histories for detonating $\mathrm{LX}-17$ and various salt crystals

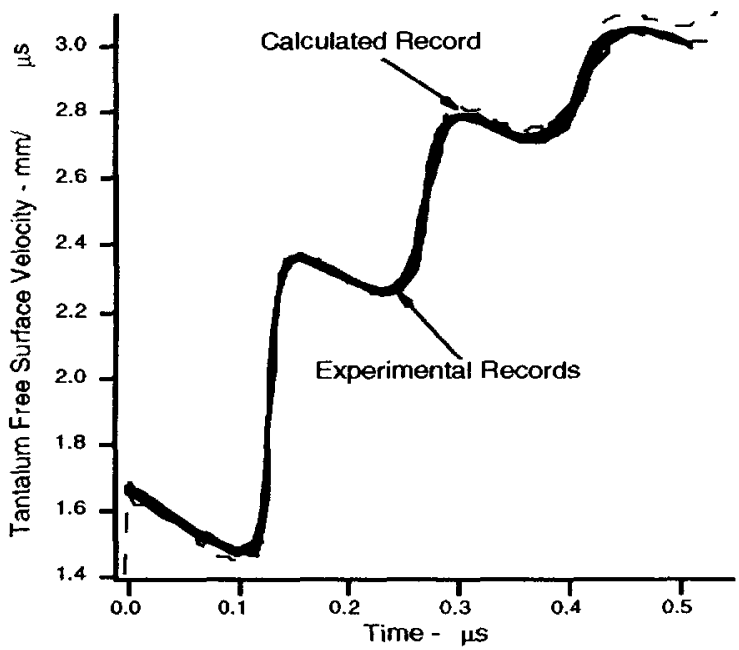

FIGURE 8. Free surface velocities for $0.267 \mathrm{~mm}$ thick tantalum disks driven by $19.871 \mathrm{~mm}$ of LX-17

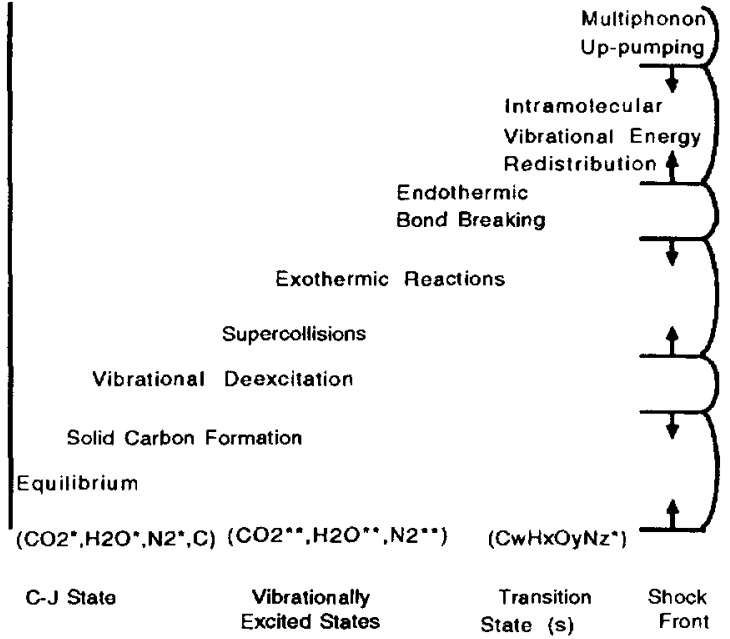

FIGURE 9. The Non-Equilibrium Zeldovich - von Neumann-Doring (NEZND) model of detonation for condensed phase explosives

Since the main application of detonating solid explosives is to accelerate metals and other materials to high velocities, an understanding of the unreacted shock state (the "von Neumann spike"), the pressure profile in the chemical reaction zone, and the subsequent expansion of the reaction products as they deliver their momentum to the metal is essential. Currently the one-dimensional averages of these properties are known to within a few percent with several nanosecond resolution $(21,31,33,34)$.

Due to solid particle interactions, one expects the detonation front structure to be more complex and less regular in heterogeneous explosives than in homogeneous ones. The sub-nanosecond techniques neoded to resolve this wave structure are becoming available. Figure 9 illustrates the various processes that precede and follow exothermic chemical reactions behind each wavelet of the threedimensional structure comprising the reaction zone of a condensed phase detonation wave. Eventually all of these non-equilibrium physical and chemical mechanisms, along with those that have not been identified as yet, will need to be measured experimentally and modeled in advanced multidimensional reaction flow models. Then the interactions of shock waves with explosive molecules and vice versa can be better understood. This understanding may lead to the production of safer, more energetic explosive molecules and formulations. 


\section{FUTURE RESEARCH}

While a great deal has been learned in recent years about the interaction of shock waves with explosive molecules, greater spatial and time resolution is needed in shock wave experiments and calculations. For understanding low velocity impact ignition mechanisms, the relative roles of void collapse, friction, shear, dislocation pile-up, etc. need to be determined by clever experimentation. Many of these postulated hot spot formation mechanisms depend upon the magnitude of the viscosity in and behind shock wave fronts, which has not yet been measured for shock waves in condensed phase explosives. If the dominant hot spot mechanism (or mechanisms) can be identified experimentally and successfully modeled, modifications to existing explosive formulations can be made. New processes and new materials (explosives, binders, additives, etc.) can be developed to produce safer products.

Since chemical reaction rates are controlled by the local temperature of a region of molecules, the most important need is for experimental measurements of temperature in all regions of shocked explosives: in and around hot spots; in deflagration waves; in the reactive flows behind shock fronts and in detonation waves. With this type of data, improved equations of state and all-Arrhenius reactive flow models can be developed to better predict the effects of shock waves on explosive molecules and vice versa (28). Eventually it will become possible to model shock induced reactions as thermal decomposition mechanisms are modeled today by identifying intermediate reaction product species and following their concentration changes. To do this effectively, nanosecond or faster time resolved experimental data on the rates of consumption of the unreacted explosive, the concentrations of intermediate species, and the rates of production of the final stable products is needed. Accurate determination of the three-dimensional structures of detonation waves in condensed phase explosives is required to determine how much detail must be included in reactive flow models to yield more realistic and predictive simulations.

\section{SUMMARY}

This short review can only begin to address the complex question: What is a shock wave to an explosive molecule? Through several compression and heating mechanisms, a shock wave is the "wake- up call" or the "trigger" by which the exothermic power of the metastable explosive moleculc is unleashed. Many possible outcomes of the initial hot spot formation process are possible: no reaction; shock desensitization; a weak explosion; a violent explosion; deflagration; shock wave formation or amplification; and transition to detonation. Detonation is of course the desired result of an intentional shock initiation but must be avoided at all costs during unintentional initiations (accidents). At the maximum rate of energy delivery in a detonation wave, the leading shock wave initiates the chemical reaction but then must be sustained by the chemical energy released. This chemical energy is initially released into highly vibrationally excited reaction products, whose relaxation to chemical equilibrium must amplify pressure wavelets propagating through the subsonic reaction zone. Understanding this intimate connection between nonequilibrium chemical kinetics and the threedimensional detonation wave structure is the key to developing improved reactive flow models and safer, more powerful explosives.

\section{ACKNOWLEDGMENTS}

The author would like to thank Jerry Forbes, Paul Urtiew, Steve Sheffield, Rick Gustavsen, David Funk, Riad Manaa, Maija Kukla, Steve Chidester, Larry Fried, Randy Simpson, Jon Maienschein, Joe Shepherd, Tom Russell, Peter Haskins, Malcom Cook, Langdon Bennett, and Mel Baer for many helpful recent discussions. None of this would have been possible without the research and friendship of many excellent scientists: Michael Cowperthwaite; Bob Woolfolk; Bob Shaw; Don Curran; Lynn Seaman; LeRoy Green; Leroy Erickson; Ed Lee; Bud Hayes; Bill Davis; Wildon Fickett; John Ramsay; John Kury; Don Breithaupt; Ray McGuire; Ed James; Bobby Craig; Pier Tang; Chuck Forest; Jace Nunziato; Albert Nichols; Dan Calef; Milt Finger; Bill Von Holle; Steve Cochran; Ron Lee; Kerry Bahl; Frank Walker; Bob Frey; Phil Howe; Joc Foster; Sig Jacobs; Steve Coffey; and many others.

This work was performed under the auspices of the U.S. Department of Energy by Lawrence Livermore National Laboratory (contract no.W-7405-ENG-48). 


\section{REFERENCES}

1. Dick, J. J., Martinez, A. R., and Hixson, R. S. Eleventh International Detonation Symposium, Office of Naval Research, ONR 33300-5, Aspen, CO, 1998, pp. 317-324.

2. Tarver, C. M., Urtiew, P. A., Chidester, S. K., and Green, L. G., Propellants, Explosives, Pyrotechnics 18,117-127 (1993)

3. Field, J. E. Boume, N. K. Palmer, S J P and Walley, S. M., Phil. Trans. R. Soc. Lond. A 339, 269-299 (1992).

4. Chidester, S. K., Tarver, C. M., and Garza, R. G. Eleventh International Detonation Symposium. Office of Naval Research, ONR 33300-5, Aspen, CO, 1998, pp. 93-100.

5. Idar, D. J., Lucht, R. A., Straight, J. W., Scammon, R. J., Browning, R. V., Middleditch, J., Dienes, J. K., Skidmore, C. B., and Buntain, G. A., Eleventh International Detonation Symposium, Office of Naval Research, ONR 33300-5, Aspen, CO, 1998, pp. $101-110$.

6. Cambell, A.W. and Travis, J. R.,Eighth Symposium (International) on Detonation, Naval Surface Weapons Center NSWC MP86-194, Albuquerque, NM 1985, pp. 1057-1068

7. Zel'dovich, Y. B. and Raizer, Y. P. Physics of Shock waves and High-Temperature Hydrodynamic Phenomena, Academic Press, NY, 1966.

8. Greene, E. F. and Toennis, J. P. Chemical Reactions in Shock Waves, Academic, NY, 1964.

9. Hong, X., Chen, S., and Dlott, D. D., J. Phys. Chem. 99, 9102-9109 (1995).

10. Holmes, W., Francis, R. S., and Fayer, M. D., J. Chem. Phys. 110, 3576-3583 (1999).

11. Weston, Jr., R. E. and Flynn, G. W. Ann. Rev. Phys. Chem. 43, 559-592 (1993).

12. Tarver, C. M. Comb. Flame 46, 111-133 (1982).

13. Bernshtein, V. and Oref, I., J. Phys. Chem. 100 , 9738-9758 (1996)

14. Tarver, C. M. Comb. Flame 46, 135-155 (1982)

15. Tarver, C. M., Comb. Flame 46, 157-179 (1982).

16. Tarver, C. M., in Shock Waves in Condensed Matter-1997, S. C. Schmidt, D. P. Dandekar, and J. W. Forbes, eds., AIP Press, 1998, pp. 301-304

17. Tarver, C. M., J. Phys. Chem. A 101 , 4845-4851 (1997).

18. Fickett, W. and Davis, W. C., Detonation, University of California Press, Berkeley, 1979.

19. Lee, J. H. S., Detonation Waves in Gaseous Explosives, in Handbook of Shock Waves, G. BenDor, O. Igra, T. Elperin, and A. Lifshitz, eds., Volume 3, Academic, NY (2001), pp. 309-415.

20. Yoo, C. S. and Holmes, N. C., in High-Pressure Science and Technoloy-1993, S. C. Schmidt, J. W. Shaner, G. Samara, and M. Ross, eds., AIP Press, New York, 1994, pp. 1567-1570.

21. Tarver, C. M., Breithaupt, R. D., and Kury, J. W., J. Appl. Phys. 81, 7193-7202 (1997).

22. Tarver, C. M. Shaw R and Cowperthwaite, $M$., J. Chem. Phys. 64, 2665-2673 (1976).

23. Kiefer, J. H and Kumaran, S. S., J. Chem. Phys. 99, $3531-3544$ (1993)

24. Green, L. G., Tarver, C. M., and Erskine, D. J. Ninth Symposium (International) on Detonation. Office of the Chief of Naval Research OCNR 113291-7, Portland, OR, 1989, pp. 670-682.

25. Eyring, H. Science 199, 740-743 (1978).

26. Schilperood, A. A., Seventh Symposium (Intemational) on Detonation, Naval Surface Warfare Center NSWC MP 82-334, Annapolis, MD, 1982, pp. 575-582.
27. Tarver, C. M., Chidester, S. K., and Nichols, A. L. III, J. Phys. Chem. 100, $5795-5799$ (1996).

28. Tarver, C. M. and Nichols, A. L. III, Eleventh International Detonation Symposium, Office of Naval Research, ONR 33300-5, Aspen, CO, 1998 , pp. 599-605.

29. Urtiew, P. A., Tarver, C. M., Forbes, J. W., and Garcia, F., in Shock Waves in Condensed Matter1997, S. C. Schmidt, D. P. Dandekar, and J. W. Forbes, eds., AIP Press, 1998, pp. 727-730.

30. Sheffield, S. A. Gustavsen, R. L. Hill, L. G., and Alcon, R. R., Eleventh International Detonation Symposium, Office of Naval Research, ONR 33300-5, Aspen, CO, 1998 pp. 451-458

31. Gustavsen, R. L., Sheffield, S. A, and Alcon, R. $\mathrm{R}$., Eleventh International Detonation Symposium, Office of Naval Research, ONR 33300-5, Aspen, CO, 1998, pp. 821-827.

32. Tarver, C. M., Hallquist, J., and Erickson, L. M., Eighth Symposium (International) on Detonation, Naval Surface Weapons Center NSWC MP86-194, Albuquerque, NM, 1985 pp. $951-961$.

33. Tarver, C. M., Kury, J. W., and Breithaupt, R. D., J. Appl. Phys. 82, 3771-3782 (1997)

34. Kury, J. W., Breithaupt, and Tarver, C. M., Shock Waves 9, 227-237 (1999). 